This document is the accepted manuscript version of the following article:

Boshoff, W., Mechtcherine, V., Snoeck, D., Schröfl, C., De Belie, N., Bettencourt Ribeiro, A. , ... Lura, P. (2020). The effect of superabsorbent polymers on the mitigation of plastic shrinkage cracking of conventional concrete, results of an inter-laboratory test by RILEM TC 260-RSC. Materials and Structures, 53(4), 79 (16 pp.).

https://doi .org/10.1617/s11527-020-01516-6

\title{
The Effect of Superabsorbent Polymers on the Mitigation of Plastic Shrinkage Cracking of Conventional Concrete, Results of an Inter-laboratory Test by RILEM TC 260-RSC
}

William Boshoffa, Viktor Mechtcherine ${ }^{b}$, Didier Snoeck ${ }^{c}$, Christof Schröfl ${ }^{b}$, Nele De Belie ${ }^{c}$, António Bettencourt Ribeiro ${ }^{d}$, Daniel Cussone, Mateusz Wyrzykowskif, Nikolajs Toropovs ${ }^{f}$, Pietro Lura ${ }^{\mathrm{f}, \mathrm{g}}$

\author{
a University of Pretoria, Pretoria, South Africa \\ b Technische Universität Dresden, Dresden, Germany \\ c Magnel-Vandepitte Laboratory for Structural Engineering and Building Materials, Ghent \\ University, Gent, Belgium \\ d National Laboratory for Civil Engineering, Lisbon, Portugal \\ e National Research Council Canada, Ottawa, Canada \\ ${ }^{f}$ Empa, Swiss Federal Laboratories for Materials Science and Technology, Switzerland \\ 9 ETH Zurich, Institute for Building Materials, Switzerland
}

\begin{abstract}
This article presents the results of an inter-laboratory study performed by six international research groups in the framework of RILEM Technical Committee 260 RSC "Recommendations for use of superabsorbent polymers in concrete construction". Two commercially available superabsorbent polymer (SAP) samples with different chemical compositions were tested in terms of their ability to mitigate plastic shrinkage cracking of concrete. The SAP mixtures showed a clear reduction of plastic shrinkage cracking in conventional concrete. On the contrary, if only additional water is added and no SAP, the area of plastic shrinkage cracks increases. This suggest the ability of SAP to mitigate plastic shrinkage cracking. Upon addition of the predetermined amount of SAP and additional water,
\end{abstract}


the compressive strength decreased on average by $3 \%$ for the mixtures with $0.15 \%$ SAP (by mass of cement) and by $10 \%$ for the mixtures with $0.30 \%$ SAP.

\section{Keywords}

Plastic shrinkage, inter-laboratory test, superabsorbent polymer, hydrogel

The study reported in this paper was performed within the framework of the RILEM TC 260 RSC "Recommendations for Use of Superabsorbent Polymers in Concrete Construction". The paper was reviewed and approved by all members of the RILEM TC 260RSC.

TC Membership:

TC Chair: Viktor Mechtcherine

Deputy TC Chair: Mateusz Wyrzykowski

Members: Livia Borba Agostinho, Fernando C.R. Almeida, Alexander Assmann, William P Boshoff, Daniel Cusson, João Custódio, Nele De Belie, Igor De la Varga, Kendra Erk, Vyatcheslav Falikman, Stefan Friedrich, Kazuo Ichimiya, Shin-Ichi Igarashi, Patricia Kara De Maeijer, Kamal H. Khayat, Agnieszka J. Klemm, Pietro Lura, Juhyuk Moon, Michaela Reichardt, Hans W. Reinhardt, António Bettencourt Ribeiro, Christof Schroefl, Didier Snoeck, Nikolajs Toropovs, Chiara Villani.

\section{Introduction}

Superabsorbent polymers (SAP) are relatively new concrete admixtures with many advantages (Mechtcherine and Reinhardt 2012; Mechtcherine 2016). The main reason why SAP were first investigated is their ability to reduce autogenous shrinkage of cement-based building materials (Jensen and Hansen 2001; Jensen and Hansen 2002; Mechtcherine et al. 2014). The reduction of autogenous shrinkage lowers the risk of cracking if the member is restrained (internally or externally). Hence, the application of SAP is especially beneficial in cementitious systems with low water-to-binder ratios $(\mathrm{w} / \mathrm{b})$, such as high to ultra-high strength concrete (Dudziak and Mechtcherine 2010; Justs et al. 2015). As the SAP cause the formation of macro pores, these pores 
are also beneficial in terms of freeze-thaw mitigation, as was studied in a previous inter-laboratory study of RILEM TC 260-RSC (Mechtcherine et al. 2017). Other applications include rheology modification (Mechtcherine et al. 2015), self-sealing (Lee et al. 2010) and self-healing (Snoeck 2018; Snoeck et al. 2014).

SAP have the ability to absorb aqueous solutions (in the particular case of concrete, pore solution) and then release these solutions when pores empty and the internal relative humidity in the cementitious system drops, in a process called internal curing. Many SAP are available on the market in different shapes, with different polymeric compositions and different absorption capacities, and only a limited few are suitable for concrete. The SAP have to be able to absorb and retain water in a highly alkaline environment in the presence of calcium ions (Zhu et al. 2015; Schröfl et al. 2014, Zhong et al. 2019) and should not disintegrate during concrete mixing. SAP are normally added to the dry constituents. Usually, additional water is added to the concrete mixture to supply the SAP with water to be absorbed (Mechtcherine et al. 2019; Snoeck et al. 2018b; Wyrzykowski et al. 2018). If the water amount to be absorbed by the SAP during mixing is not accounted for in the mix design, the workability is substantially reduced, which can be compensated by increasing dosage of superplasticizer. Internal curing by means of SAP has been shown in numerous studies as an effective method against autogenous shrinkage. On the other hand, no systematic study regarding the effect of SAP on plastic shrinkage cracking has been reported so far. This paper addresses this issue.

Plastic shrinkage cracking is a phenomenon that occurs in the fresh state of concrete, normally within a few hours after the concrete has been placed and finished (Boghossian and Wegner 2008). The mechanism can be summarized as follows: Bleeding of the concrete water starts directly after the concrete is cast, which goes hand in hand with the consolidation/settlement of the concrete. This bleed water is vital for the protection of the fresh concrete as once the total evaporation exceeds the bleed water, the rapid drying of the concrete starts which causes high capillary pressures in the cementitious material whose stiffness increases rapidly at the same time (both due to hydration of cement and capillary pressure stiffening). This in turn leads to the build-up of selfinduced stresses, which consequently cause cracking ( Slowik et al. 2008; Wittmann 1976; Combrinck and Boshoff 2013; Ghourchian et al. 2018; Ghourchian et al. 2019). If sufficient bleeding water is available, the cracking can be reduced. However, if the evaporation rate is severe (typically more than $1 \mathrm{~kg} / \mathrm{m}^{2} / \mathrm{h}$ ), bleeding is not sufficient and different means of preventing cracking are required ( American Concrete Institute 2007; Ghourchian et al. 2017; Ghourchian et al. 2018). 
The most common way to mitigate plastic shrinkage cracking is by reducing the evaporation locally at the surface of the concrete. These methods include covering the concrete with plastic sheets, adding windbreaks and sun protection, applying curing agents, and, lastly, using a fog spray over the surface of the concrete. The application of such methods is however often omitted in practice due to high workload and costs. Another popular way to mitigate plastic shrinkage is to reduce the cracking by an internal approach (so-called passive methods), namely adding micro polypropylene fibres (Banthia and Gupta 2006; Soroushian et al. 1993), natural fibres (Boghossian and Wegner 2008), shrinkage reducing agents (Leemann et al. 2014; Ghourchian et al. 2018; Lura et al. 2007).

Internal curing by means of pre-wetted lightweight aggregates has been shown to be effective in reducing plastic shrinkage cracking (Henkensiefken et al. 2010). Wyrzykowski et al. (2015) showed with neutron tomography that the lightweight aggregates were able to release internal curing water already in the plastic stage. Some results have been also published about internal curing by SAP. As the SAP possess the ability to induce internal curing, this feature can be used to mitigate plastic shrinkage as well. When spherical SAP with size of $150 \mu \mathrm{m}$ in an amount of $0.6 \%$ by mass of cement were added to cement pastes with a basic water-to-cement $(\mathrm{w} / \mathrm{c})$ ratio of 0.265 along with additional water corresponding to an additional w/c of 0.087 , the capillary pressures and plastic deformations were reduced while the settlement deformations increased (Dudziak and Mechtcherine 2010). Serpukhov and Mechtcherine (2015) showed that the addition of SAP to both ordinary concrete and strain-hardening cement-based composite (SHCC) clearly reduced the capillary pressure within fresh materials under hot climate conditions as well as plastic shrinkage and cracking propensity.

In a recent study, Nuclear Magnetic Resonance was used to study the water release kinetics with SAP when plastic shrinkage conditions (i.e. rapid evaporation when the concrete was still plastic) were imposed (Snoeck et al. 2018a). The SAPs were able to reduce plastic settlement and plastic shrinkage but were not able to eliminate it (Snoeck et al. 2018a). The water release kinetics by the SAP were a key parameter when investigating plastic shrinkage. Besides, an investigation of the sorption kinetics of two distinct SAP samples by neutron radiography imaging of fresh, uncovered cement pastes disclosed a pronounced decrease of the cracking propensity. It was shown that the inherently desorbing SAP was slightly less efficient than the retentive SAP, which only desorbs its intaken liquid upon demand, i.e. upon severe drying or water consumption by the accelerating phase of cement hydration (Schröfl et al. 2019). 
Some publications thus point to the possibility of using SAP to mitigate plastic shrinkage cracking. In this paper, the use of SAP in conventional concrete to mitigate plastic shrinkage is examined within a RILEM inter-laboratory test programme in which six laboratories participated. This paper presents the results of the test programme and makes inferences on the use of SAP for the mitigation of plastic shrinkage cracking in conventional concrete. The inter-laboratory test programme was commissioned by Working Group 2 of the RILEM Technical Committee 260-RSC, titled "Recommendations for Use of Super-absorbent Polymers in Concrete Construction". The participants from six countries and three continents are shown in Table 1. Initially, the effect of two different dosages of SAP compared to the control mix was tested and constituted Set 1 of the tests. At a later stage, second set of tests was carried out, where the effect of additional water (without any SAP) was studied. Because the second set of tests was carried out at a later stage, and a possible variation of the materials could have taken place, that set also consisted of the repeated control mix and the mix with the same amount of additional water and SAP. The scheme of the tests done in different sets is presented in Table 2. It should be noted that for Laboratory 6, all the tests of Set 1 and additional test of the control mix with extra water were done in one set of experiments on the same batch of materials in a short time window (about 1 month).

Table 1. List of participating laboratories

\begin{tabular}{ccc}
\hline Laboratory Number & Institution & Country \\
\hline $\mathbf{1}$ & Laboratório Nacional de Engenharia Civil & Portugal \\
\hline $\mathbf{2}$ & National Research Council Canada & Canada \\
\hline $\mathbf{3}$ & Stellenbosch University & South Africa \\
\hline $\mathbf{4}$ & Technische Universität Dresden & Germany \\
\hline $\mathbf{5}$ & University of Ghent & Belgium \\
\hline $\mathbf{6}$ & Empa & Switzerland \\
\hline
\end{tabular}

Table 2. The test programme

SAP (by mass of cement) Set 1 Set 2

\begin{tabular}{cccc}
\hline Control & $0 \%$ & $\mathrm{X}$ & $\mathrm{X}$ \\
\hline SAP 1 & $0.15 \%$ & $\mathrm{X}$ & \\
\hline SAP 1 & $0.30 \%$ & $\mathrm{X}$ & $\mathrm{X}$ \\
\hline Control + Add water 1* & $0 \%$ & & $\mathrm{X}$ \\
\hline SAP 2 & $0.15 \%$ & $\mathrm{X}$ & \\
\hline SAP 2 & $0.30 \%$ & $\mathrm{X}$ & $\mathrm{X}$ \\
\hline
\end{tabular}


* Additional water is the same as that determined for the mix with $0.30 \%$ SAP

\section{Specifications}

The inter-laboratory tests were done in two sets, referred to as Set 1 and Set 2 in this paper. Set 1 consisted of five mixtures, namely a control mix, and mixes with 0.15\% SAP 1 and SAP 2 and 0.30\% SAP 1 and SAP 2 (all percentages of dry SAP are by mass of cement). Set 2 included a control, and mixtures with $0.30 \%$ SAP 1 and SAP 2 and an additional mixture that contained the same amount of extra water needed for the SAP mixtures, but with no added SAP. This extra set was aimed at indicating whether the change of plastic cracking behaviour of concrete containing SAP was due to the added SAP, or due to the net effect of additional water.

An important aspect of these SAP mixtures is that the additional water required for the SAP absorption was not determined beforehand by a tea-bag test or similar test (Snoeck et al. 2018b). Instead, the amount of additional water was ascertained by adding water to the SAP concrete mixture until the same slump was obtained as in the control mixture without SAP (Mechtcherine et al. 2019; Wyrzykowski et al. 2018).

The concrete mixture to be used only had a few limited specifications while the SAP were supplied to ensure all mixtures from the different participating laboratories used the same SAP. There were two SAP used, labelled as SAP 1 and SAP 2 in this paper. Slump, setting time, compressive strength, bleeding and plastic shrinkage cracking tests were also specified and are detailed in the following sections after the mixture specifications.

The SAP were distributed from a single source while all other concrete materials were locally sourced.

\subsection{Mixture specification}

A conventional concrete mixture was to be used with only the following specifications:

- The $w / c$ of the control mix should be 0.5 ;

- Cement of strength 42.5 should be used and it can be either CEM I, CEM II or CEM III, or equivalent (depending on local availability); 
- The maximum aggregate size should be between $13 \mathrm{~mm}$ and $16 \mathrm{~mm}$;

- For the SAP mixtures, additional water should be added to the concrete "on top" of the mix design to ensure the same slump as the reference ( $0 \% \mathrm{SAP})$ mixture. This must be recorded and expressed as (g additional water) / (g SAP);

- The SAP must be added at both $0.15 \%$ and $0.30 \%$ concentrations (by mass of cement) for Set 1 and only $0.30 \%$ for Set 2 ;

- The mixtures with additional water without additional SAP (Set 2) should get the same amount of additional water as determined for the corresponding mixture with $0.30 \% \mathrm{SAP}$;

- The target slump should be $120 \mathrm{~mm}( \pm 15 \mathrm{~mm})$ for all mixtures, except the mixtures of Set 2 with just the additional water. The last mentioned mixture had no target slump (adding additional water without SAP should increase the slump considerably);

- The slump test should be done exactly 10 minutes after the water was added to the dry constituents;

- The mixture should exhibit limited bleeding to ensure plastic shrinkage cracking. The mixture should exhibit no visible segregation.

SAP 1 is a covalently cross-linked poly acrylate while SAP 2 is a covalently cross-linked poly(acrylateco-acrylamide) with qualitatively intermediate crosslinking density. SAP 1 has higher cross-linking density than SAP 2. Both polymer materials were used "as-delivered" in their original form and size grading. SAP 1 shows self-releasing (non-retentive) behaviour; in free absorption tests it initially absorbs water and later releases most of the water. SAP 2 shows a retentive type of absorption behaviour; the absorbed pore solution is retained by the SAP over a long period. Supposedly, it is only released as a response to an external trigger, e.g. capillary suction when used in cement paste (Schroefl et al. 2015). It is hence expected that mixtures with SAP 1 will show increased bleeding compared to SAP 2. Please note that the denomination of SAP 1 and SAP 2 is the same in the present paper as in Schroefl et al. (2015) and Schröfl et al. (2019).

\subsection{Test specification}

A number of tests were specified to obtain a comprehensive understanding of the effect of SAP addition on fresh and hardened concrete properties. The tests are: plastic shrinkage cracking, bleeding, setting time, slump test, compressive strength and pore pressure development. The specifications for these tests are explained in the following paragraphs. 
Plastic shrinkage cracking tests according to ASTM C1579 were specified. Variations of the mould geometry were allowed, e.g. increasing the restraint to increase the probability of occurrence and the magnitude of cracking. It was preferred that three to four samples be tested per mixture variation to obtain representative information on the crack widths or areas, respectively. The ASTM C1579 prescribes cracks to be measured $24 \pm 2$ hours after the mixing of the concrete, but another appropriate time and justified by physical reasoning, e.g. at final set, can be used if it is done consistently.

ASTM C232 or a similar method was recommended for the measurement of the bleeding. The setting times were to be tested on sieved concrete samples using the Vicat setup, penetrometer or any other appropriate method. The compressive strengths could be performed according to local standards, on either cylinders or cubes.

\section{Actual Test setups}

The recommended specifications were mostly followed, with few exceptions. Also, these results are included, but qualified where appropriate. The individual test setups used by each laboratory are presented in the following sections.

\subsection{Setting time test setups}

Laboratories 1, 2 and 5 all used the penetrometer approach of ASTM C403/C403M for the setting times. The containers used for Laboratory 1 were $150 \mathrm{~mm}$ cubic moulds while Laboratory 2 used 250 $\mathrm{mm}$ cubic moulds. All three laboratories stored the specimens in the same conditions as for their plastic shrinkage cracking tests.

Laboratory 3 used a Vicat test method for determining the setting time of the concrete. The concrete was first sieved through a $4.75 \mathrm{~mm}$ sieve to obtain a mortar and placed in the same environmental conditions as the plastic shrinkage tests.

\subsection{Bleeding test setup}


Laboratories 1, 2, 3 and 5 all used the bleeding test setup prescribed by ASTM C232/232M. The container dimension for Laboratory 1 is $200 \mathrm{~mm}$ in diameter and a height of $270 \mathrm{~mm}$, and for Laboratory 2 the diameter was 255 and a height of $280 \mathrm{~mm}$. Laboratory 3 used containers with the same height as the plastic shrinkage cracking moulds. The containers used by Laboratory 5 were exactly 1 litre in volume and the same height as the plastic shrinkage tests. All moulds were exposed to the same environmental conditions as the plastic shrinkage tests, however using a cover to prevent evaporation. Laboratory 6 measured bleeding according to the standard EN 480-4:2005. The container used had a diameter of $250 \mathrm{~mm}$ and a height of $250 \mathrm{~mm}$ and it was filled with 12 litres of concrete.

\subsection{Plastic shrinkage cracking test setups}

A summary of the environmental conditions of the plastic shrinkage cracking environments can be seen in Table 3.

Table 3. The environmental conditions of the plastic shrinkage cracking tests for each laboratory [L\#] for each Set $[\mathrm{S \#}]$

\begin{tabular}{|c|c|c|c|c|c|c|c|c|c|}
\hline & L1S1 & L1S2 & L2S1 & L3S1 & L3S2 & L4S1 & L5S1 & L5S2 & L6S2 \\
\hline Temperature $\left[{ }^{\circ} \mathrm{C}\right]$ & $38-42$ & 39 & $24-32$ & 40 & 40 & 30 & $30-35$ & $30-35$ & $33 \pm 0.5$ \\
\hline Wind speed $[\mathrm{m} / \mathrm{s}]$ & 6.2 & 6.2 & $2.5-2.9$ & 6.25 & 6.25 & 5.8 & $\begin{array}{l}5.5- \\
6.5\end{array}$ & $\begin{array}{l}5.5- \\
6.5\end{array}$ & 7.5 \\
\hline Relative humidity [\%] & $31-34$ & $\begin{array}{c}23.5- \\
30.5\end{array}$ & $37-51$ & 10 & 10 & 40 & $35-45$ & $35-45$ & $35 \pm 5$ \\
\hline $\begin{array}{c}\text { Concrete temperature at } \\
\text { start of test }\left[{ }^{\circ} \mathrm{C}\right]\end{array}$ & $19-24$ & $18-19$ & 23 & 22 & 22 & 35 & $23-24$ & $23-24$ & $\begin{array}{l}19.3- \\
21.4\end{array}$ \\
\hline $\begin{array}{c}\text { Evaporation rate } \\
\qquad\left[\mathrm{kg} / \mathrm{m}^{2} / \mathrm{h}\right]\end{array}$ & $\begin{array}{l}1.07- \\
1.16\end{array}$ & $\begin{array}{c}0.85- \\
0.98\end{array}$ & $\begin{array}{l}0.42- \\
0.80\end{array}$ & 1 & 1 & 2 & $\begin{array}{l}1.03- \\
1.14\end{array}$ & $\begin{array}{l}1.46- \\
1.82\end{array}$ & $\begin{array}{l}0.60- \\
0.64\end{array}$ \\
\hline
\end{tabular}

All laboratories ran their plastic shrinkage tests based on the ASTM C1579-13 standard with the following exceptions or modifications. Laboratories 1,5 and 6 used a walk-in chamber with precisely controlled climate rather than an enclosed environmental chamber. The airflow was created by a fan on the same level as the samples. The rest of the setups were climatic chambers as illustrated in ASTM C1579-13. Two additional $10 \mathrm{~mm}$ steel reinforcing bars were inserted in the prescribed mould with risers by Laboratory 3 to increase the restraint, thus increasing the plastic shrinkage cracking. 
Laboratories 1 and 2 used a crack comparator to measure the crack at at least ten points over the stress riser in a progressive order from one side of the panel to the other, avoiding measurements within $25 \mathrm{~mm}$ of test panel boundaries. The cracks were measured every $10 \mathrm{~mm}$ along the length of the crack using a C \& D crack-scope with an optical magnification of $40 \times$ and a $0.02 \mathrm{~mm}$ resolution. Laboratory 3 used high-resolution photos which were scaled in CAD software using a ruler on the samples. The crack width for every $10 \mathrm{~mm}$ of crack length was measured and the average reported. Laboratories 4 and 6 used a digital image processing approach where high resolution photos of the cracked surfaces were taken and processed to measure the crack widths. The crack widths were determined by Laboratory 6 at 10- $\mathrm{mm}$ intervals (neglecting the zones $25 \mathrm{~mm}$ from the edges of the samples) along the cracks formed over the stress risers. The cracks were measured every $20 \mathrm{~mm}$ along their length by Laboratory 5 using a crack microscope.

\subsection{Capillary pressure test setup}

Laboratory 6 measured the evolution of capillary pressure in the concrete. This was measured by tensiometers with ceramic heads (T5-10 by UMS). The tensiometers were placed in fresh concrete through holes in one of the moulds with stress risers at mid-height of the concrete layer. Two tensiometers for each concrete mixture were used.

\subsection{Summary of test configurations}

Table 4 shows a summary of which sets and tests were done by the different laboratories.

Table 4. Summary of which laboratory performed which sets and tests

\begin{tabular}{rcccccc} 
& \multicolumn{6}{c}{ Laboratory } \\
\cline { 2 - 7 } & 1 & 2 & 3 & 4 & 5 & 6 \\
\hline Set 1 & X & X & X & X & X & X \\
\hline Set 2 & X & & X & & X & X \\
\hline Slump & X & X & X & X & X & X \\
\hline Setting times & X & X & X & & X & \\
\hline Bleeding & $\mathrm{X}$ & $\mathrm{X}$ & $\mathrm{X}$ & $\mathrm{X}$ & $\mathrm{X}$ & $\mathrm{X}$ \\
\hline Plastic Shrinkage cracking & $\mathrm{X}$ & $\mathrm{X}$ & $\mathrm{X}$ & $\mathrm{X}$ & $\mathrm{X}$ & $\mathrm{X}$ \\
\hline Pore pressure & & & & & & $\mathrm{X}$ \\
\hline
\end{tabular}




\section{Test results}

The specifications for the mixture design were on purpose not stringent, so relatively large variations were found in the mixture designs of the different laboratories. However, the results were always compared to the control of the specific laboratory, so the normalised results can still be compared between laboratories, increasing the data set to verify the extent of mitigation of plastic shrinkage by the SAP. Not all laboratories took part in both Sets 1 and 2 .

\subsection{Actual mixture designs}

The actual mixture designs of each laboratory are shown in Table 5. The mixing water content of the concretes varied from $142 \mathrm{~kg} / \mathrm{m}^{3}$ to $230 \mathrm{~kg} / \mathrm{m}^{3}$ while the cement content also varied accordingly to ensure a constant water/cement ratio of 0.50 . Laboratory 1 used a retarder while Laboratories 4 and 6 used a superplasticiser to control the slump. The mixtures also varied slightly between Set 1 and Set 2 of the participating laboratories. The additional water added to compensate for the absorption of the SAP was not included in the mixture designs shown in Table 5. This amount was determined in order to obtain the same workability as the reference mixture, i.e. the same slump flow value at the time specified for this test. The SAPs and the additional water were added to the concrete on top of the mixture design.

Table 5. The mixtures used by each laboratory [L\#] for each Set [S\#]. This excludes the SAPS and additional water added for the SAP, which were added "on top", which means extra water was added without being taken into account in the mix design.

\begin{tabular}{ccccccccccc}
\hline$\left[\mathrm{kg} / \mathrm{m}^{3}\right]$ & L1S1 & L1S2 & L2S1 & L3S1 & L3S2 & L4S1 & L5S1 & L5S2 & L6S1 & L6S2 \\
\hline Water & 142 & 178 & 220 & 230 & 223 & 175 & 172 & 172 & 175 & 175 \\
\hline Cement & $357^{1}$ & $346^{1}$ & $440^{2}$ & $460^{3}$ & $445^{4}$ & $350^{5}$ & $344^{6}$ & $344^{6}$ & $350^{5}$ & $350^{5}$ \\
\hline W/C & 0.4 & 0.52 & 0.5 & 0.5 & 0.5 & 0.5 & 0.5 & 0.5 & 0.5 & 0.5 \\
\hline Coarse aggregate & 1291 & 1229 & 880 & 1000 & 1000 & 903 & 1352 & 1352 & 914.5 & 914.5 \\
\hline Sand & 662 & 737 & 660 & 665 & 730 & 922 & 552 & 552 & 915 & 915 \\
\hline Admixture & $3.21^{7}$ & $3.11^{7}$ & & & & $33^{8}$ & & & $0.7^{8}$ & $0.7^{8}$
\end{tabular}

${ }^{1}$ CEM I 42.5 R

${ }^{2}$ OPC GU (Type 1)

${ }^{3}$ CEM II 42.5 N B-M (L-S)

${ }^{4}$ CEM III 42.5 N B-M (L-S)

${ }^{5}$ CEM II 42.5 N A-LL 
${ }^{6} \mathrm{CEM}$ I $42.5 \mathrm{~N}$

${ }^{7}$ Retarder

${ }^{8}$ Superplasticiser

The additional water required for each mixture to ensure the same slump after SAP is added is shown in Table 6. Laboratories 1, 3 and 6 adjusted each mixture to ensure the same slump while Laboratories 4 and 5 used one value for both SAP volumes and types, but still obtained similar slump values. Laboratory 2 did not add any additional water.

It is interesting to note that for both Laboratories 1 and 3, the water required for SAP 1 in the second set was significantly reduced compared to Set 1 while Laboratory 5 required the same additional water for both sets. It is however similar to Set 1 results of other laboratories. This decrease in additional water means the absorption capacity of SAP 1 was reduced during the time from Set 1 to Set 2. Laboratories 5 and 6 stored the SAP in opaque and moisture-sealed containers to prevent preliminary absorption and UV degradation (Mechtcherine et al. 2018). The negligible reduction of Laboratory 5 SAP 1 absorption capacity compared to the other laboratories supports the recommendation to store SAP in the in the absence of light and moisture.

Table 6. The additional water added to the mixtures to compensate for the loss of water due to the SAP absorption. It is indicated as the additional water (g) per mass dry SAP (g) that was added.

\begin{tabular}{cccccccccc}
\hline$[\mathrm{g} / \mathrm{g}]$ & L1S1 & L1S2 & L2S1 & L3S1 & L3S2 & L4S1 & L5S1 & L5S2 & L6S1 \\
\hline SAP 1 0.15\% & 22.8 & & 0 & 25 & & & 27 & 27 & \\
\hline SAP 1 0.30\% & 19.7 & 6.85 & 0 & 22 & 10 & 27 & 27 & 27 & \\
\hline SAP 2 0.15\% & 15.2 & & 0 & 23 & & & 27 & 27 & 25.63 \\
\hline SAP 2 0.30\% & 19.2 & 18.67 & 0 & 22 & 23 & 27 & 27 & 27 & 35.95 \\
\hline
\end{tabular}

The actual slump values are shown in Table 7. All the laboratories, except Laboratories 2 and 5, were close to the specified $120 \pm 15 \mathrm{~mm}$. Laboratory 2 , who only did Set 1 , did not add any additional water to their mixtures with SAP, therefore it is expected that the slump values would decrease, as they did, with an increase of SAP dosage. Note that the Ctrl + Add water 1 and 2 mixtures were supposed to have higher slump as additional water was added to the concrete without any addition of SAP. This is the same amount of water that would have been added if the respective SAP were added at $0.30 \%$ by mass of cement.

Table 7. The slump values of each mixture 


\begin{tabular}{cccccccccc}
\hline Slump Values [mm] & L1S1 & L1S2 & L2S1 & L3S1 & L3S2 & L4S1 & L5S1 & L5S2 & L6S1 \\
\hline Control & 105 & 130 & 225 & 120 & 125 & 170 & 130 & 160 & 110 \\
\hline SAP 1 0.15\% & 110 & & 225 & 120 & & & 140 & 160 & \\
\hline SAP 1 0.30\% & 110 & 125 & 210 & 120 & 130 & 210 & 150 & 165 & \\
\hline Ctrl + Add water 1 & 180 & & & 155 & & & 215 & \\
\hline SAP 2 0.15\% & 110 & & 218 & 120 & & 130 & 160 & 110 \\
\hline SAP 2 0.30\% & 100 & 120 & 148 & 120 & 120 & 200 & 140 & 160 & 115 \\
\hline Ctrl + Add water 2 & & 205 & & & 190 & & 215 & 220 \\
\hline
\end{tabular}

\subsection{Setting times}

The initial and final setting times are shown in Table 8. The long setting times found by Laboratory 1 were due to the retarder added. The effect of SAP on the setting times is shown to be small and no clear trend could be found.

Table 8. The initial and final setting times of the different concrete mixtures (the missing entries were not reported).

\begin{tabular}{cccccccc}
\hline Initial / Final [min] & L1S1 & L1S2 & L2S1 & L3S1 & L3S2 & L5S1 & L5S2 \\
\hline Control & $825 / 1280$ & $1100 / 1180$ & $276 / 348$ & $145 / 190$ & $140 / 180$ & $163 / 255$ & $226 / 368$ \\
\hline SAP 1 0.15\% & $1015 / 1145$ & & $228 / 312$ & $140 / 190$ & & $163 / 255$ & $253 / 385$ \\
\hline SAP 1 0.30\% & $1075 / 1240$ & $1095 / 1150$ & $258 / 336$ & $145 / 210$ & $160 / 180$ & $167 / 265$ & $265 / 397$ \\
\hline Ctrl + Add water 1 & & $1140 / 1200$ & & & $140 / 160$ & $257 / 396$ \\
\hline SAP 2 0.15\% & n/a / 1140 & & $258 / 354$ & $150 / 210$ & $165 / 258$ & $252 / 388$ \\
\hline SAP 2 0.30\% & n/a / 1340 & $1280 / 1360$ & $210 / 294$ & $130 / 190$ & $140 / 180$ & $166 / 263$ & $262 / 391$ \\
\hline Ctrl + Add water 2 & & $1060 / 1120$ & & & $160 / 180$ & & $257 / 396$ \\
\hline
\end{tabular}

\subsection{Bleeding}

The bleeding results show a significant difference between concrete with and without SAP, although there was quite some variability between the participating laboratories. The bleeding results are shown in Figures 1 and 2 for SAP 1 and SAP 2 respectively. These are expressed as a percentage of the control. 


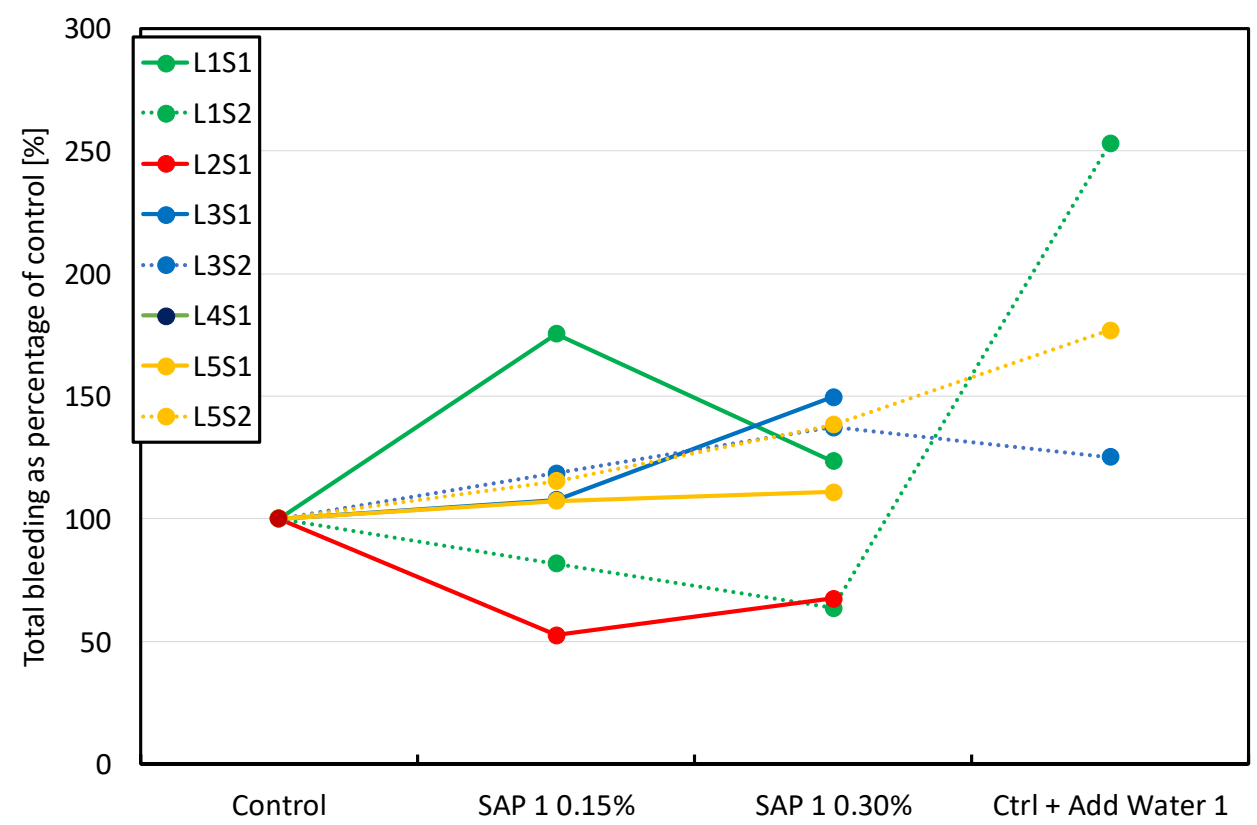

Figure 1. The bleeding for SAP 1 expressed as a percentage of the control.

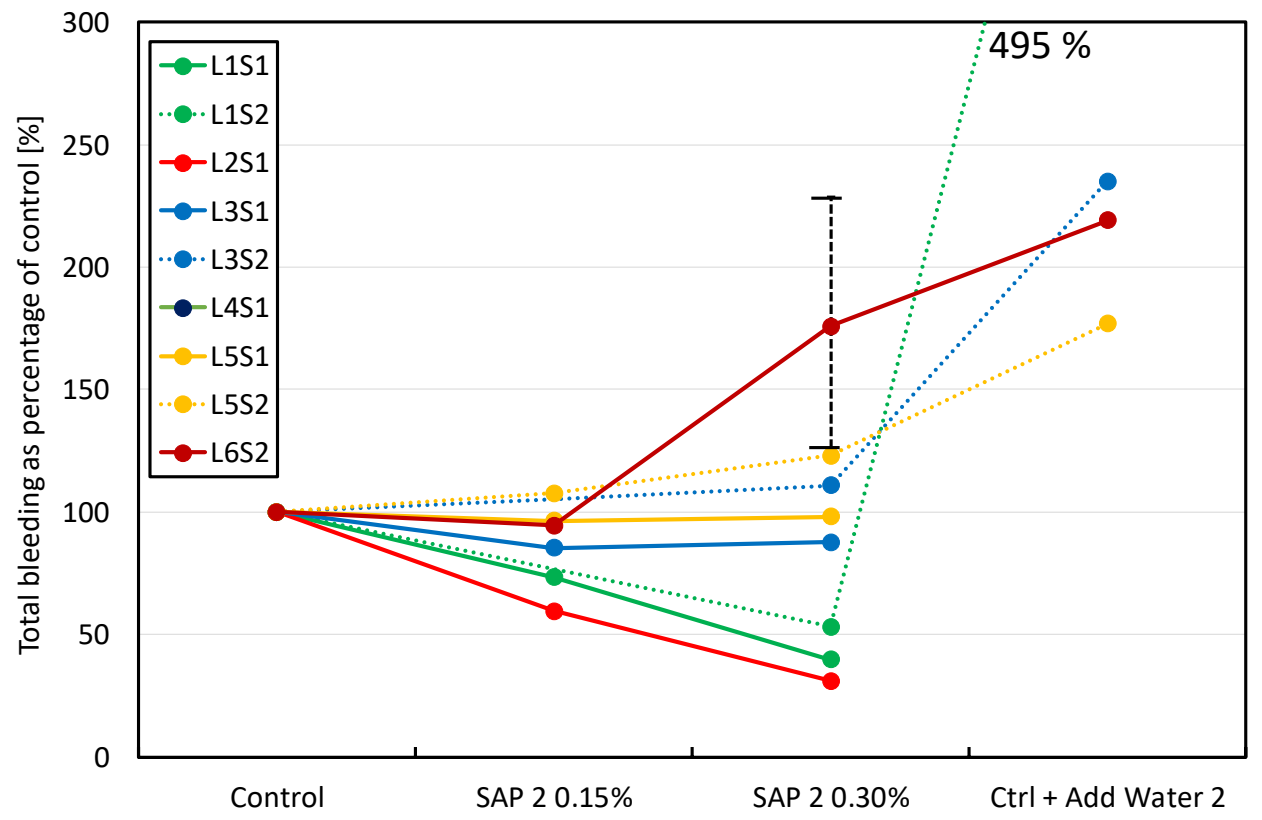

Figure 2. The bleeding for SAP 2 expressed as a percentage of the control. The error bars are showing the minimum and maximum values for a specific test result.

SAP 1 (Figure 1) showed more erratic bleeding results compared to SAP 2 (Figure 2). In most cases, the addition of SAP 1 at increasing dosage increased the bleeding, which is expected due to the inherent sorptivity behaviour of SAP 1, which easily releases the absorbed water again (so-called self-releasing SAP). This resulted in a smaller difference with the mixes including the additional water without the SAP, compared to the case of SAP 2. Note that Laboratory 3 did not show this 
increase for SAP 1, but rather for SAP 2. This can be ascribed to the reduced additional water required for SAP 1 in Set 2 to ensure the same slump.

The bleeding results of SAP 2 (Figure 2) looks fairly consistent between the laboratories. There is a gradual decrease of the amount of bleeding water as the SAP volume is increased with a large spike in the bleeding when only the extra water was added without the SAP. This is expected. However, Laboratories 1 and 2 showed the lowest bleeding for the mixtures with SAP. For Laboratory 2 this is expected, as no additional water was added to compensate for the water absorbed by SAP 2. For Laboratory 1 this decrease could be ascribed to the significantly lower amount of additional water to compensate for SAP that was added compared to the other laboratories, see Table 6 .

Increased bleeding was observed for SAP 2 0.30\% in Laboratory 6 who did two tests for each data point, as shown in Figure 2. Most likely part of the additional water could not be absorbed by the SAP in the concretes tested in Laboratory 6 . The two test results also indicate the possible scatter of these tests with the error bars indicating the minimum and maximum values. The main reason for the large scatter is due to a likely shift in the time at which concrete was cast in the test vessel (for later casting, the amount of bleeding is reduced).

\subsection{Compressive strength}

The compressive strength values are shown in Table 9. Note that all the laboratories performed their tests using cubes except Laboratory 2, which used cylinders. The compressive strength as a percentage of the control is shown in Figures 3 and 4 for SAP 1 and SAP 2, respectively, and the average of the compressive strength as percentage of the control is shown in Table 10. The compressive strength values of Laboratory 2 were not included in Table 10, as they did not add any additional water for their SAP mixtures which is not in line with the test program prescribed here.

Table 9. The compressive strength values at 28 days (average \pm standard deviation)

\begin{tabular}{|c|c|c|c|c|c|c|c|c|c|}
\hline [MPa] & L1S1 & L1S2 & L2S1 & L3S1 & L3S2 & L4S1 & L5S1 & L5S2 & L6S2 \\
\hline Control & $53.9 \pm 0.3$ & $60.0 \pm 0.4$ & $44.0 \pm 1$ & $42.3 \pm 0.8$ & $44.8 \pm 0.2$ & $45.5 \pm 2.5$ & $39.5 \pm 2.3$ & $43.6 \pm 2.1$ & $39.1 \pm 0.4$ \\
\hline SAP $10.15 \%$ & $56.6 \pm 1.0$ & & $46.3 \pm 0.6$ & $42.3 \pm 0.5$ & & & $37.3 \pm 1.3$ & $39.8 \pm 1.5$ & \\
\hline SAP $10.30 \%$ & $51.5 \pm 0.3$ & $55.2 \pm 2.3$ & $45.0 \pm 2.2$ & $38.7 \pm 1.2$ & $42.8 \pm 0.8$ & $32.3 \pm 1.5$ & $30.9 \pm 1.1$ & $36.1 \pm 1.1$ & \\
\hline Ctrl + Add water 1 & & $55.5 \pm 1.1$ & & & $41.3 \pm 1.5$ & & & $37.6 \pm 7.2$ & \\
\hline SAP $20.15 \%$ & $54.3 \pm 2.8$ & & $45.3 \pm 1.0$ & $41.1 \pm 1.6$ & & & $38.2 \pm 0.9$ & $40.1 \pm 1.3$ & $37.6 \pm 0.7$ \\
\hline SAP $20.30 \%$ & $57.0 \pm 1.0$ & $56.0 \pm 2.3$ & $45.4 \pm 0.6$ & $39.7 \pm 1.0$ & $39.7 \pm 0.8$ & $41.9 \pm 0.6$ & $33.4 \pm 1.8$ & $36.7 \pm 1.8$ & $40.9 \pm 0.5$ \\
\hline
\end{tabular}




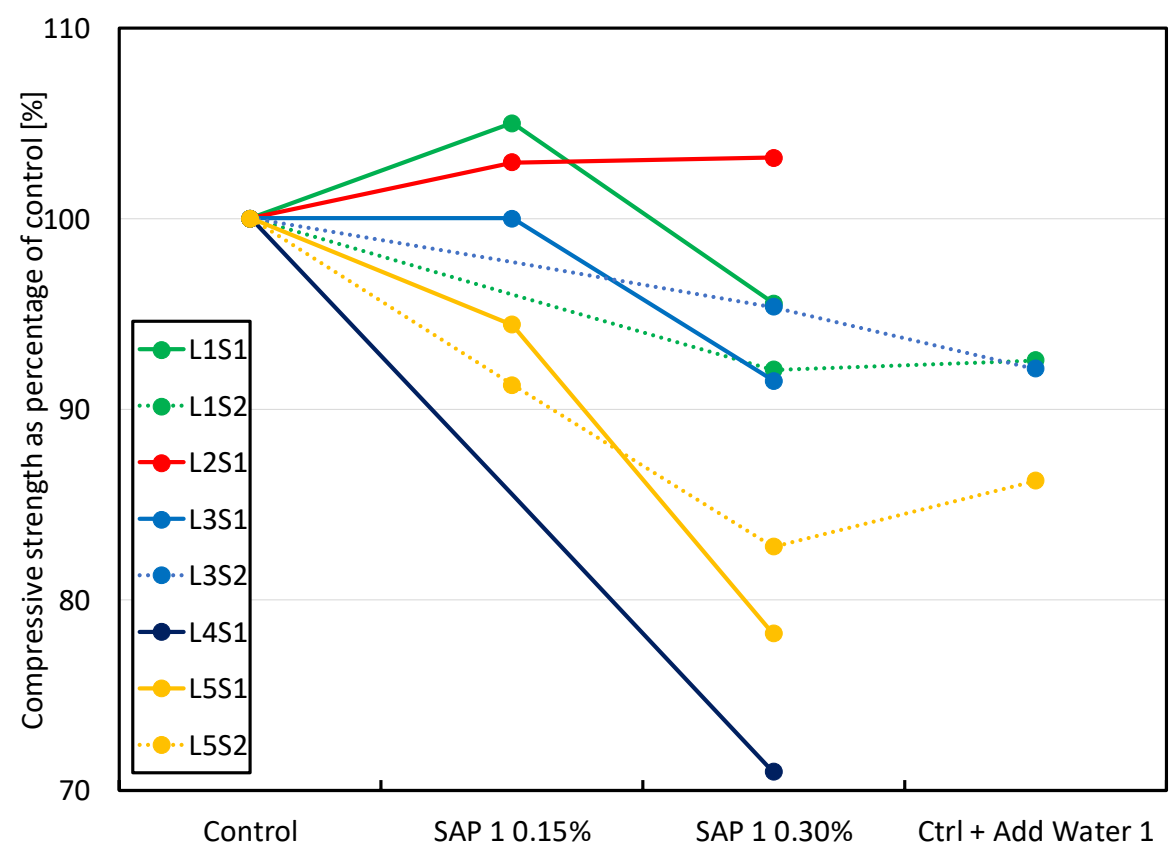

Figure 3. Compressive strengths as a percentage of the control for SAP 1.

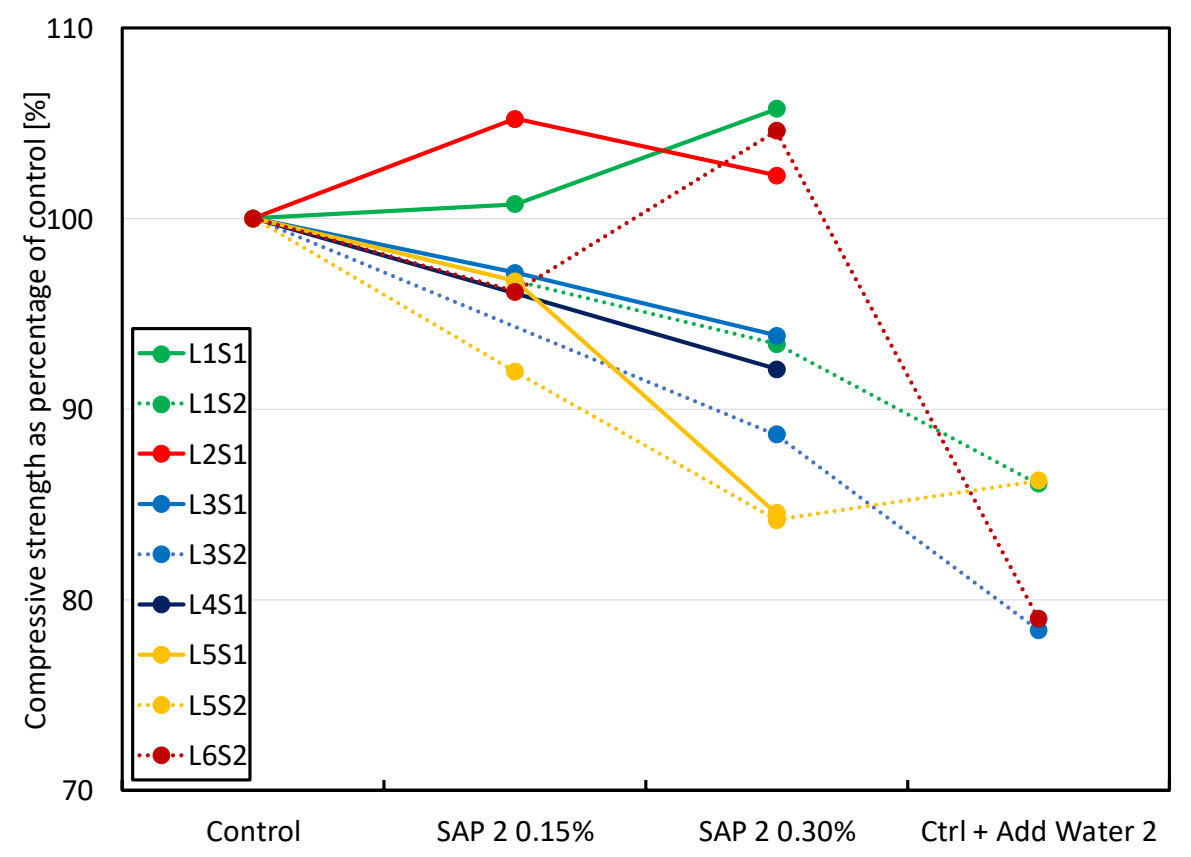

Figure 6. Compressive strengths as a percentage of the control for SAP 2. 
Table 10. The average of the compressive strengths as a percentage of the control. Note that the results of Laboratory 2 are not included as mentioned earlier in this section. Standard deviation is calculated between the average values of different laboratories

\begin{tabular}{lcc}
\hline & [\%] & $\begin{array}{c}\text { Standard deviation } \\
{[\% \text { points] }}\end{array}$ \\
\hline Control & 100.0 & - \\
\hline SAP 1 0.15\% & 97.7 & 6.1 \\
\hline SAP 1 0.30\% & 86.6 & 9.5 \\
\hline Ctrl + Add water 1 & 90.3 & 3.5 \\
\hline SAP 2 0.15\% & 96.6 & 3.1 \\
\hline SAP 2 0.30\% & 93.4 & 8.2 \\
\hline Ctrl + Add water 2 & 82.4 & 4.3 \\
\hline
\end{tabular}

In general, adding SAP and additional water leads to a reduction in the compressive strength which is fully in line with the vast majority of results reported to date. The reduction is more prominent for SAP 1 with the compressive strength of $0.30 \%$ SAP 1 at $86.6 \%$ of the control, while for SAP 2 this value is $93.4 \%$. This can be explained based on the nature of the different SAP. SAP 2 retains water for a longer time, only releasing it to compensate for drying. The major effect of SAP 2 on strength would be in such case just by introduction of the macroscopic pores (remnants of initially swollen SAP). On the other hand, SAP 1 is known to release the absorbed water without any external force during free absorption tests. When used in a concrete mixture, it is possible that such premature release could have led to actual increase of the basic w/c compared to SAP 2. In a previous study (Mechtcherine et al. 2017), it was shown that a reference concrete and concrete with SAP, both with the same w/c, had similar mechanical properties. Hence, the effect of additional porosity, either in form of large pores (corresponding to SAP 2 concrete) or higher capillary porosity (corresponding to SAP 1 concrete), can be expected to be similar with regard to strength. At the same time, the earlier release of water could also contribute to segregation which can also result in a more pronounced decrease of compressive strength in concrete SAP 1 . The problems related to a premature absorption could be especially acute if the premature release took place before casting or vibration. This was likely the case in the tests presented here. When adding just the additional water without the SAP, the compressive strength dropped by $10 \%$ and $18 \%$, for the amounts of additional corresponding to those in concretes with SAP 1 and SAP 2, respectively.

\subsection{Plastic shrinkage cracking}


The plastic shrinkage cracking tests were all quantified in terms of either crack widths or crack areas. Due to the difference in the mixtures between the laboratories, the different test setups and environmental conditions, the crack widths and areas cannot be compared between laboratories. However, the effect of SAP on the crack areas can be compared if all the results are normalised with regard to the control concrete within each laboratory. The plastic shrinkage cracking results, as a percentage of the control, are shown in Figures 5 and 6 for SAP 1 and SAP 2 respectively. These values are also presented in Table 11 with the standard deviation. The average crack areas / widths are shown in Table 12. Note that the results of Laboratory 2 are neglected in this calculation as their evaporation rates varied significantly between the different tests.

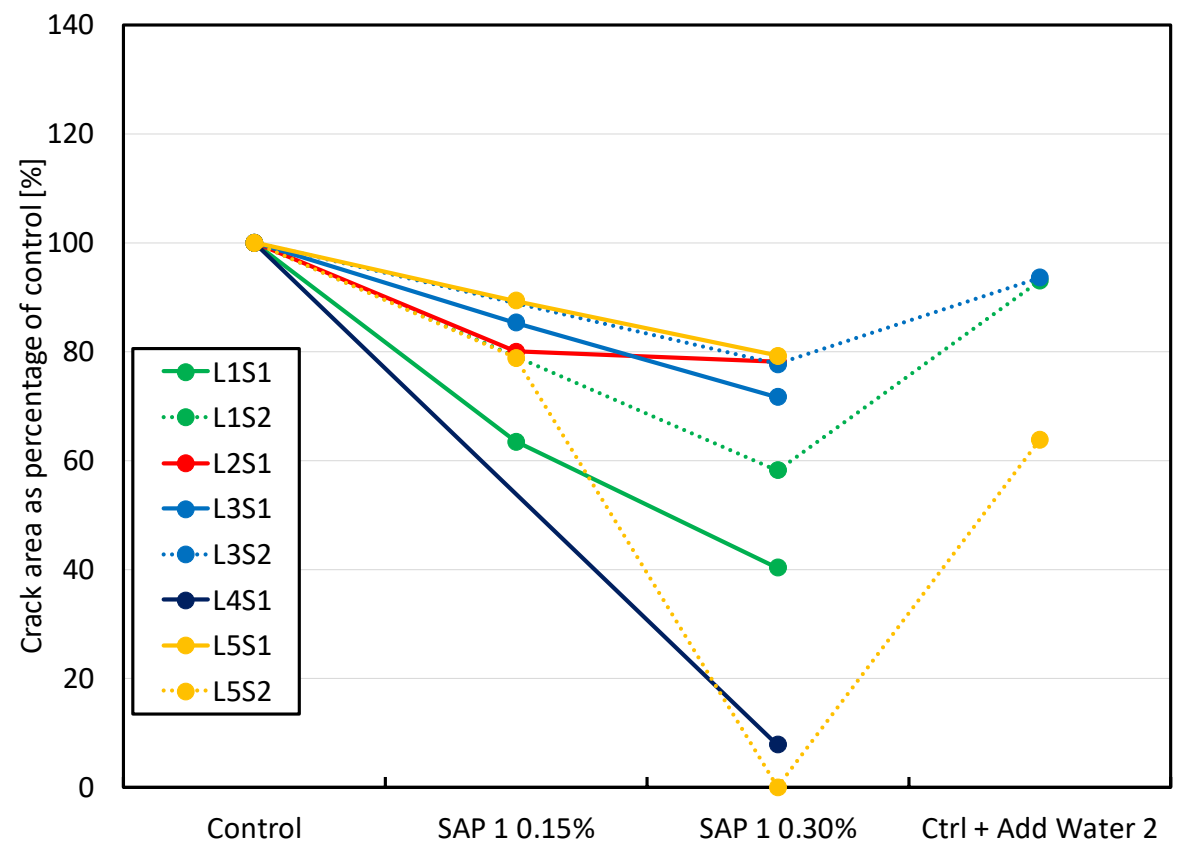

Figure 5. The plastic shrinkage crack area / width as a percentage of the control for SAP 1 


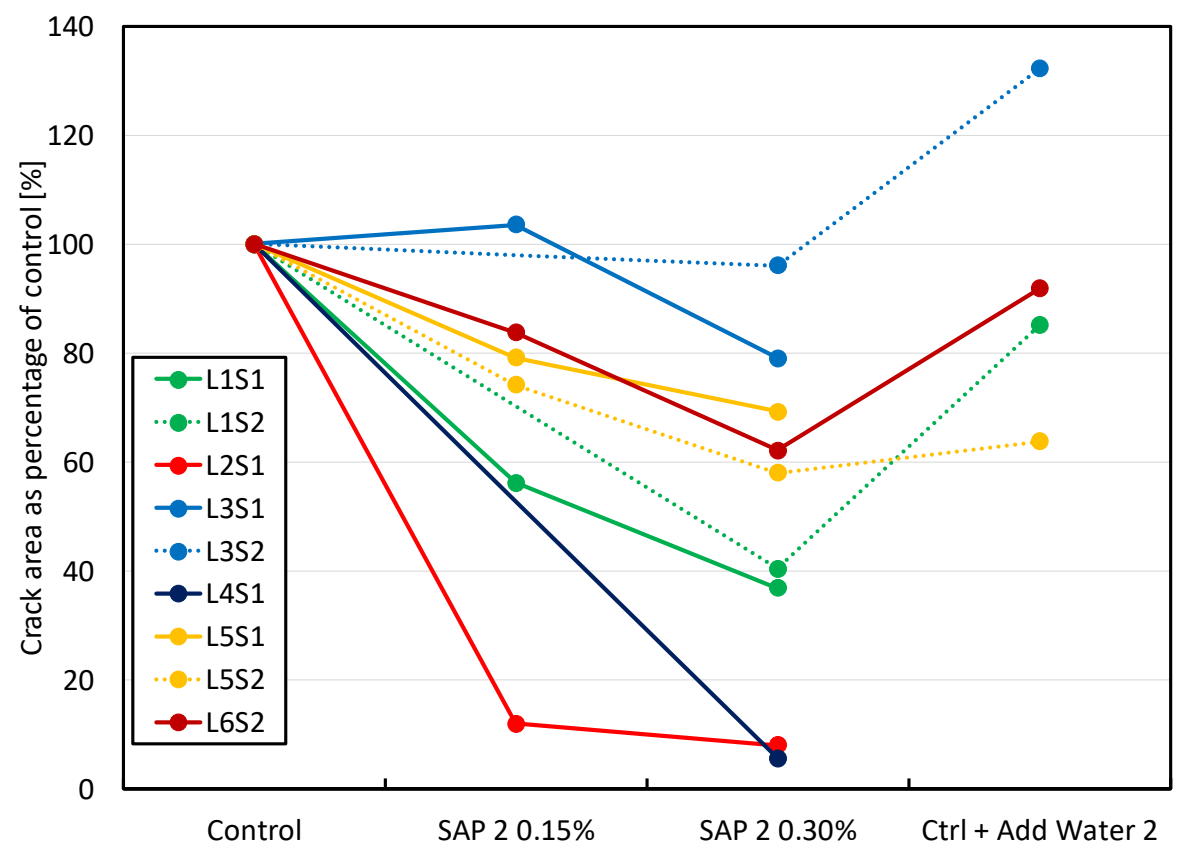

Figure 6. The plastic shrinkage crack area as a percentage of the control for SAP 2

Table 11. Plastic shrinkage cracking area/width as a percentage of the control with the standard deviation included.

\begin{tabular}{cccccccccc}
\hline & L1S1 & L1S2 & L2S1 & L3S1 & L3S2 & L4S1 & L5S1 & L5S2 & L6S1 \\
\hline Control & $100 \pm 20$ & 100 & $100 \pm 18.4$ & $100 \pm 20.2$ & $100 \pm 19.2$ & 100 & $100 \pm 11.3$ & $100 \pm 21$ & $100 \pm 37.8$ \\
\hline SAP 1 0.15\% & $63.4 \pm 30$ & & $80 \pm 38.5$ & $85.3 \pm 17$ & & 53.895 & $89.3 \pm 11.4$ & $78.8 \pm 24.6$ & - \\
\hline SAP 1 0.30\% & $40.3 \pm 40$ & 58.2 & $78 \pm 26.3$ & $71.6 \pm 0.2$ & $77.6 \pm 13.4$ & 7.79 & $79.2 \pm 14$ & $0 \pm 0$ & \\
\hline Ctrl + Add water 1 & & 92.9 & & & $93.5 \pm 30.5$ & & & $63.8 \pm 35.4$ & \\
\hline SAP 2 0.15\% & $56.2 \pm 29$ & & $12 \pm 33.3$ & $103.6 \pm 9.72$ & & 52.83 & $79.2 \pm 12$ & $74.2 \pm 35.9$ & $83.8 \pm 45.2$ \\
\hline SAP 2 0.30\% & $36.9 \pm 40$ & 40.4 & $8 \pm 0$ & $79.1 \pm 10.2$ & $96 \pm 25.4$ & 5.66 & $69.3 \pm 12.7$ & $58 \pm 37.5$ & $62.2 \pm 73.9$ \\
\hline Ctrl + Add water 2 & & 85.1 & & & $132.2 \pm 21.3$ & & & $63.8 \pm 35.4$ & $91.9 \pm 52.9$ \\
\hline
\end{tabular}

Table 12. The average plastic shrinkage cracking area / width as a percentage of the control.

\begin{tabular}{lcc} 
& {$[\%]$} & $\begin{array}{c}\text { Standard deviation } \\
{[\% \text { points] }}\end{array}$ \\
\hline Control & 100 & - \\
\hline SAP 1 0.15\% & 79.2 & 11.4 \\
\hline SAP 1 0.30\% & 47.8 & 32.9 \\
\hline Ctrl + Add water 1 & 83.4 & 17.0 \\
\hline SAP 2 0.15\% & 79.4 & 17.1 \\
\hline SAP 2 0.30\% & 55.9 & 28.0 \\
\hline Ctrl + Add water 2 & 93.3 & 28.6 \\
\hline
\end{tabular}


Except for one data point that was slightly higher (103.6\% for L3S1 SAP $20.15 \%$ ), all mixtures with SAP showed a reduction in plastic shrinkage cracking when compared to the control. For both SAP 1 and SAP 2, this reduction increased with an increase of dosage of SAP. This was obtained for SAP 2 even though the bleeding of the SAP 2 mixtures was smaller than the control. A decrease of bleeding would normally be expected to increase the plastic shrinkage cracking.

For the Ctrl + Add. water 1 and 2 mixtures, the plastic shrinkage cracking was mostly also reduced when compared to the control. This is expected, as additional water without SAP would increase the bleeding, hence reduce the plastic shrinkage cracking. However, for both SAP 1 and SAP 2, (in conjunction with their respectively added amount of extra water) reduced the plastic shrinkage cracking significantly more compared to the Ctrl + Add Water mixtures. This result clearly demonstrates that the decrease of plastic shrinkage cracking when SAP are added is not due to just the additional water, as the additional water on its own does not reduce the plastic shrinkage cracking as much. In conclusion, SAP plays an important role in reducing the plastic shrinkage cracking, other than just supplying extra water.

The mechanism of how SAP reduced plastic shrinkage cracking is not yet fully clear. It is not due to the uncontested release of the water, as the bleeding did not increase for mixtures with SAP 2. Therefore, the cracking is not reduced due to the increase of bleed water. First results related to water migration in this context have most recently been published (Schröfl et al. 2019) but further investigations are due.

The volumetric change that results in plastic shrinkage cracking is caused by capillary action, which builds up the negative internal pore pressure, thus causing a reduction in volume of concrete. If this reduction of volume is restrained, cracking occurs. One mechanism that could be the reason for the improved performance with SAP, is that the SAP release the water when the capillary pressure is building up. By compensating for the lost water, they reduce the capillary pressure and decrease the volume change. On the contrary, the internal curing water would normally not be released during the bleeding tests, as there is no capillary pressure build up during this test. The hypothetical action of SAP during plastic shrinkage is supported by the additional results of Laboratory 6 , where capillary pressure evolution in concrete was measured, see Figure 7. Average curves of two measurements per sample are shown with standard deviation at chosen time points. It was observed that the concretes SAP $20.15 \%$, SAP 2 0.30\% and Ctrl + Add water 2 experienced slower evolution of capillary pressure between the time of about $3 \mathrm{~h}$ from casting and setting time, and the effect was 
particularly visible for the higher dosage of SAP. With respect to the effect of SAP addition on capillary pressure and plastic shrinkage, these results agree with those reported earlier by Serpukhov and Mechtcherine (2015).

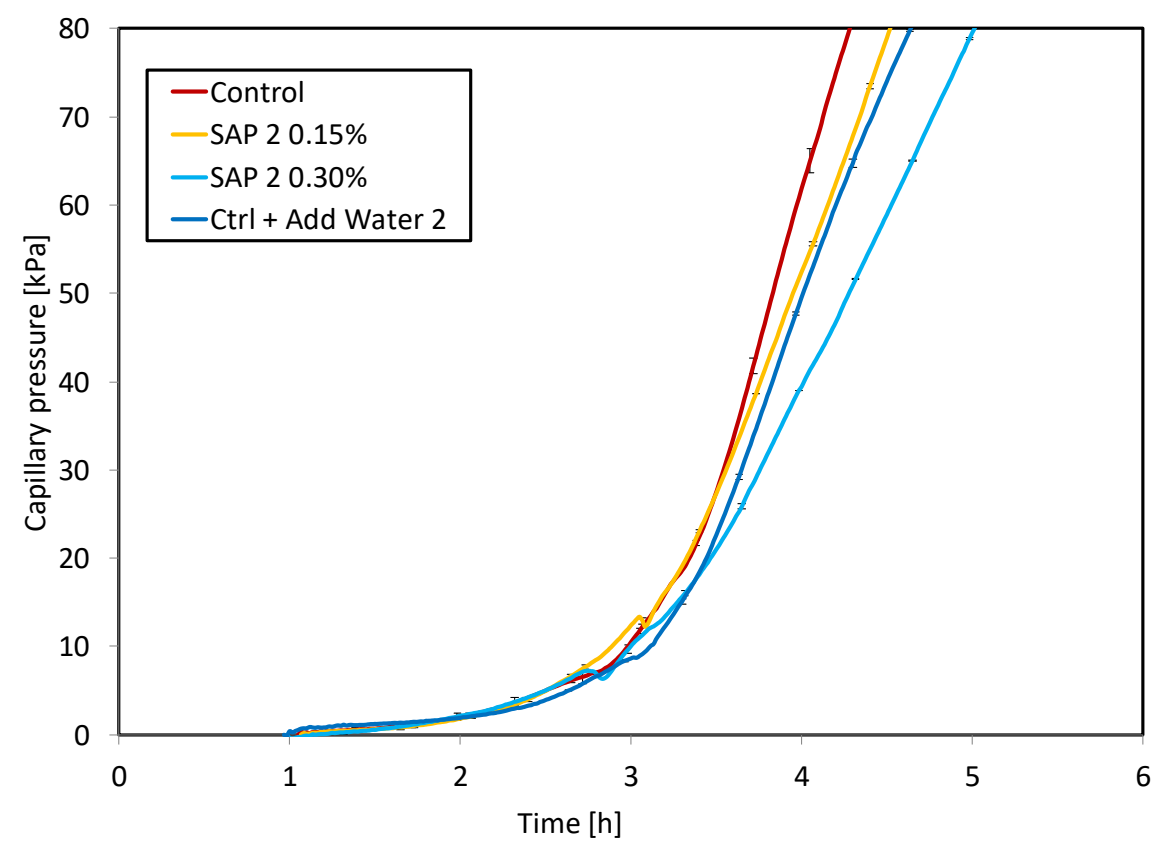

Figure 7. The capillary pressure development as determined by Laboratory 6 for SAP 2 .

Another phenomenon that may result in cracking of fresh concrete is plastic settlement, in particular differential settlement that occurs over reinforcement or where the height of the concrete section changes (Kwak et al. 2010, Moradllo et al. 2019). In many cases, cracking in fresh concrete may result from the superposition of stresses caused both by settlement and drying (Qi et al. 2005). As shown in Figure 2, the addition of retentive SAP (SAP 2) reduces bleeding and thereby also is expected to reduce consolidation and settlement of fresh concrete (though no measurements of settlement are reported in this paper). At the same time, the internal curing water stored in SAP 2 is released into the matrix as well as to the ambient air according to a "demand-and-supply" mechanism (Schröfl et al. 2019). This supply of water mitigates plastic shrinkage cracks (Figure 6). The faster pressure buildup of Ctrl + Add. water 2 comparing to SAP $20.30 \%$ may be caused by different permeabilities of the fresh concretes. Obviously, adding water directly affects the permeability of the fresh concrete more than the same amount of water stored inside SAP and released in time.

\section{Conclusions}


This paper presents the results of an inter-laboratory test programme to determine the effect of superabsorbent polymers (SAPs) on the plastic shrinkage cracking of conventional concrete. The following conclusions were made:

- The majority of tests (26 out of 27 ) revealed that adding SAP to conventional concrete, together with the appropriate amount of additional internal curing water, reduced the severity of plastic shrinkage cracking. This occurred both for SAP that retain the absorbed water(so-called retentive SAP) and for SAP that release their water prematurely.

- When just the same amount of additional water was added, but without SAP, the plastic shrinkage cracking was more significant than for the mixtures with both SAP and additional water. It can be concluded that SAP does indeed reduce plastic shrinkage cracking and that it is not just due to the additional water.

- Bleeding is influenced not only by the addition of SAP, but also by the type of SAP employed. The SAP with higher long term fluid retention ability by itself reduced the bleeding compared to the other SAP which only had only short-term absorption capacity. The latter increased the bleeding, contrarily to the first type.

- When SAP is added to conventional concrete with just enough additional water to ensure the same slump as the control, a slight decrease of the compressive strength can be found. In this study, the compressive strength was found to be on average $97 \%$ of the control for the $0.15 \%$ SAP mixtures and $90 \%$ of the control for the $0.30 \%$ SAP mixtures. This will have to be determined for each mixture made with SAP for the mitigation of plastic shrinkage cracking.

\section{Acknowledgements}

V. Mechtcherine gratefully acknowledges the support provided by Deutsche Forschungsgemeinschaft (DFG, German Research Foundation), Project Number 424803818 (ME 2938/23-1). As a Postdoctoral Research Fellow of the Research Foundation-Flanders (FWO-Vlaanderen), D. Snoeck would like to thank the foundation for the financial support (12J3620N). The contribution of Pretoria Portland Cement, South Africa, is much appreciated by W. Boshoff.

\section{Declaration on conflict of interest}

The authors declare that they have no conflict of interest. 


\section{References}

- American Concrete Institute (2007) Specification for Hot Weather Concreting. American Concrete Institute, Farmington Hills, USA

- Banthia N, Gupta R (2006) Influence of polypropylene fiber geometry on plastic shrinkage cracking in concrete. Cement and Concrete Research 36:1263-1267

- Boghossian E, Wegner LD (2008) Use of flax fibres to reduce plastic shrinkage cracking in concrete. Cemement of Concrete Composites 30:929-937

- Combrinck R, Boshoff WP (2013) Typical plastic shrinkage cracking behaviour of concrete. Magazine of Concrete Research 65:486-493

- Dudziak L, Mechtcherine V (2010) Enhancing early-age resistance to cracking in highstrength cement based materials by means of internal curing using super absorbent polymers. In: Brameshuber W (ed) International RILEM Conference on Material Science, Aachen, 2010. RILEM Publications S.A.R.L., pp 129-139

- Ghourchian S, Wyrzykowski M, Lura P, (2017) A practical approach for reducing the risk of plastic shrinkage cracking of concrete. RILEM Technical Letters 2: 40-44.

- Ghourchian S, Wyrzykowski M, Lura P, (2018) A poromechanics model for plastic shrinkage of fresh cementitious materials. Cement and Concrete Research 109: 120-132.

- Ghourchian S, Wyrzykowski M, Plamondon M, Lura P, (2019) On the mechanism of plastic shrinkage cracking in fresh cementitious materials. Cement and Concrete Research 115: 251-263.

- Henkensiefken R, Briatka P, Bentz D, Nantung T and Weiss J, (2010) Plastic shrinkage cracking in internally cured mixtures made with pre-wetted lightweight aggregate. Concrete international, 32(2), pp.49-54.

- Jensen OM, Hansen PF (2001) Water-entrained cement-based materials I. Principles and theoretical background. Cement and Concrete Researh 31:647-654

- Jensen OM, Hansen PF (2002) Water-entrained cement-based materials II. Experimental observations. Cement and Concrete Researh 32:973-978

- Justs J, Wyrzykowski M, Bajare D, Lura P (2015) Internal curing by superabsorbent polymers in ultra-high performance concrete Cement and Concrete Researh 76:82-90

- Kwak HG, Ha S, Weiss WJ (2010) Experimental and numerical quantification of plastic settlement in fresh cementitious systems, Journal of materials in Civil Engineering 22(10):951-966

- Leemann, A, Nygaard, P, Lura, P(2014) Impact of admixtures on the plastic shrinkage cracking of self-compacting concrete. Cement and Concrete Composites 46:1-7

- Lee HXD, Wong HS, Buenfeld NR (2010) Potential of superabsorbent polymer for selfsealing cracks in concrete. Advanced Applied Ceramics 109:296-302

- Lura P, Pease B, Mazzotta GB, Rajabipour F, Weiss J (2007) Influence of shrinkagereducing admixtures on development of plastic shrinkage cracks. ACI Materials Journal, 104(2):187

- Mechtcherine, V (2016) Use of superabsorbent polymers (SAP) as concrete additive. RILEM Technical Letters 10:81-87.

- Mechtcherine V et al. (2014) Effect of Internal Curing by Using Superabsorbent Polymers (SAP) on Autogenous Shrinkage and Other Properties of a High-performance Finegrained Concrete: Results of a RILEM Round-robin Test, TC 225-SAP. Material and Structures 47:541-562

- Mechtcherine V, Reinhardt HW (eds) (2012) Application of Super Absorbent Polymers (SAP) in Concrete Construction. State-of-the-Art Report Prepared by Technical Committee 225-SAP. Springer. 
- Mechtcherine V, Schröfl C, Reichardt M, Klemm AJ, Khayat KH (2019) Recommendations of RILEM TC 260-RSC for using superabsorbent polymers (SAP) for improving freezethaw resistance of cement-based materials. Materials and Structures 52:1-7

- Mechtcherine V et al. (2017) Effect of superabsorbent polymers (SAP) on the freezethaw resistance of concrete: results of a RILEM interlaboratory test. Materials and Structures 50:1-19

- Mechtcherine V, Secrieru E, Schröfl C (2015) Effect of superabsorbent polymers (SAPs) on rheological properties of fresh cement-based mortars - Development of yield stress and plastic viscosity over time. Cement and Concrete Researh 67:52-65

- Mechtcherine V et al. (2018) Testing superabsorbent polymer (SAP) sorption properties prior to implementation in concrete: results of a RILEM Round-Robin Testm Materials and Struct ures 51:28

- Moradllo MK, Reese SR, Weiss WJ (2019) Using Neutron Radiography to Quantify the Settlement of Fresh Concrete, Advances in Civil Engineering Materials 8(1):71-87

- Qi C, Weiss J, Olek J (2005) Assessing the settlement of fresh concrete using a noncontact laser profiling approach, In Int. Conf. on Construction Materials: ConMat'05.

- Schroefl, C, Mechtcherine, V, Vontobel, P, Hovindb, J, Lehmann, B (2015) Sorption kinetics of superabsorbent polymers (SAPs) in fresh Portland cement-based pastes visualized and quantified by neutron radiography and correlated to the progress of cement hydration, Cement and Concrete Research 75:1-13

- Schröfl C, Snoeck D, Mechtcherine V (2017) A review of characterisation methods for superabsorbent polymer (SAP) samples to be used in cement-based construction materials - Report of the RILEM TC 260-RSC. Maters and Structures 50:1-19

- Schröfl C, Mechtcherine, V., Mannes, D., 2019, Dewatering Kinetics from Fresh Cement Pastes Enriched with Superabsorbent Polymer (SAP) Samples at Ambient and Elevated Temperatures Visualised and Quantified by Neutron Radiography Imaging, Proceedings of SAP2019, Skukuza, South Africa, pp 123-131.

- Serpukhov I, Mechtcherine, V (2015) Early-Age Shrinkage of Ordinary Concrete and a Strain-Hardening Cement-Based Composite (SHCC) in the Conditions of Hot Weather Casting. Proceedings of the 10th International Conference on Mechanics and Physics of Creep, Shrinkage, and Durability of Concrete and Concrete Structures CONCREEP 2015, pp 1504-1513

- Slowik V, Schmidt M, Fritzsch R (2008) Capillary pressure in fresh cement-based materials and identification of the air entry value. Cement Concrete Composites 30:557565

- Snoeck D (2018) Superabsorbent polymers to seal and heal cracks in cementitious materials. RILEM Technical Letters 3:32-38

- Snoeck D, Pel L, De Belie N (2018a) Superabsorbent polymers to mitigate plastic drying shrinkage in a cement paste as studied by NMR. Cement and Concrete Composites 93:54-62

- Snoeck D, Schröfl C, Mechtcherine V (2018b) Recommendation of RILEM TC 260-RSC: testing sorption by superabsorbent polymers (SAP) prior to implementation in cementbased material. Maters and Structures 51:1-7

- Snoeck D, Van Tittelboom K, Steuperaert S, Dubruel P, De Belie N (2014) Self-healing cementitious materials by the combination of microfibres and superabsorbent polymers. Journal of Intelligent Material Systems and Structures 25:13-24

- Soroushian P, Mirza F, Alhozajiny A (1993) Plastic Shrinkage Cracking of Polypropylene Fiber Reinforced Concrete. Materials Journal 92:553-560

- Wittmann FH (1976) On the action of capillary pressure in fresh concrete. Cement and Concrete Research 6:49-56 
- Wyrzykowski M, Igarashi S-I, Lura P, Mechtcherine V (2018) Recommendation of RILEM TC 260-RSC: using superabsorbent polymers (SAP) to mitigate autogenous shrinkage. Materials and Structures 51:1-7

- Wyrzykowski M, Trtik P, Münch B, Weiss J, Vontobel P and Lura P, (2015) Plastic shrinkage of mortars with shrinkage reducing admixture and lightweight aggregates studied by neutron tomography. Cement and Concrete Research, 73, pp.238-245.

- Zhong P, Wyrzykowski M, Toropovs N, Li L, Liu J and Lura P, (2019) Internal curing with superabsorbent polymers of different chemical structures. Cement and Concrete Research, 123, 105789.

- Zhu, Q, Barney CW, Erk, KA, (2015), Effect of lonic Crosslinking on the Swelling and Mechanical Response of Model Superabsorbent Polymer Hydrogels for Internally Cured Concrete, Materials and Structures, Vol 48, pp 2261-2276 